\title{
Gallbladder Hyperplastic Polyp
}

National Cancer Institute

\section{Source}

National Cancer Institute. Gallbladder Hyperplastic Polyp. NCI Thesaurus. Code C7417.

A polypoid tumor that arises from the gallbladder. It is characterized by the presence of elong ated, serrated crypts lined by proliferative epithelium. 